\title{
HYDRAULIC CHARACTERISTICS OF FLOW OVER AND UNDER SEMI- CYLINDRICAL STRUCTURE
}

\author{
Shaker Abdulatif Jalil, Sarhan Abdulsatar Sarhan and Jihan Mahmood Qasim \\ Dept. of Water Resources Engineering, College of Engineering, University of Duhok, Kurdistan Region-Iraq
}

(Received: June 5, 2018; Accepted for Publication: August 13, 2018)

\begin{abstract}
In this study the germane factors influencing the flow over and under semi-cylindrical structure are experimentally investigated. Four different diameters are tested, each one is operated with four different heights of gate opening to yield sixteen models. For the purpose of comparison, a vertical rectangular thinplate model is tested. Performance of the semi-cylindrical structure proved to be significantly better than the rectangular model. The laboratory investigations show that at low flow heads that just caused to start operating the weirs, the increase in gate opening from 2 to $5 \mathrm{~cm}$ caused an increase in total discharge about $80 \%$, but it decreased to $3 \%$ with an increase in head about $50 \%$. In addition, the effect of cylinder diameter decreased at relatively high heads for all gate openings when the ratio of head/gate-opening increased to 2 . The contribution of weir flow hinders gate flow causing its submergence and thus the head on the weir relatively increased at an average of $34 \%$. The dimensionless parameters that cause increasing or decreasing the total dimensionless discharge are discussed. The contribution of weir in the total actual discharge is between $7 \%-44 \%$ and that of gate is between $56 \%-93 \%$, depending on gate opening and cylinder diameter. Mathematical models are presented to predict the total discharge and the contribution of weir and gate with considerable accuracy.
\end{abstract}

KEYWORDS: Combined Weir-Gate Structure; Combined Flow; Semi-Cylindrical Weir; SemiCylindrical Gate

\section{INTRODUCTION}

W hen water flows simultaneously over the weir and below the gate in a combined structure, a mutual effect happens between the two discharge components until stabilization. The nature laws of reciprocal affect each part managing the upstream head of the total flow. Several factors take control in this flow situation that needs to be investigated.

The combined gate-weir structure incorporates the operational advantages of both the weir and the gate. It can be used for many purposes such as flow measurement, diversion and regulation, and also for silt-flushing. The suspended particles deposited in the upstream pool formed by a weir result in a gradual change in the discharge coefficient (Chow, 1959).On the other hand, floating materials are retained upstream the gate. Both disadvantages can be overcome by the use of the combined gate-weir structure that acts as a self-cleaning device.
Alhamid et al. (1996) studied the contracted rectangular sharp-crested weirs and below inverted V-notches, and proposed discharge equations for free and submerged flow conditions. Alhamid et al. (1997) also investigated a thinplate V-notch weir combined with a contracted rectangular sluice gate, and suggested a discharge equation for the free flow condition. Alhamid (2000) used a combined weir-gate device in circular sewer for flow measurement. Negm et al. (2002) investigated experimentally the combined flow over contracted sharp-crested rectangular weirs and below contracted rectangular gates and introduced an equation for the modular limit to calculate the limiting tail water depth ratio.

Negm (2002) also studied the flow over contracted rectangular weirs and below contracted rectangular gates of unequal contractions and proposed an equation for computing the simultaneous discharge and compared its results to the results of an artificial neural network (ANN) model. Hayawi et al. (2008) studied the characteristics of free flow through triangular 
weirs combined with a rectangular gate. Dehghani et al. (2010) and Shahabi et al. (2011) investigated experimentally the scouring downstream of the combined structure and showed that the main part of scour is due to flow over the weir and that the maximum scour depth in combined structure is less than that in separate weir and gate. Jalil and Sarhan (2013) experimentally studied oblique sharp-crested thin plates as combined weir-gate structures. Khassaf et al. (2013) and Khassaf and Abbas (2013) studied the discharge coefficient of compound sharp-crested weirs combined with a sluice gate having a semicircular opening. Masoudian et al. (2013) studied the effects of the canal size on the discharge coefficient of cylindrical weir-gate using two flumes, and presented a discharge equation for each canal. It was shown that the discharge coefficient rises in small canals due to increasing the ratio of upstream water depth to gate opening, and the ratio of upstream water depth to structure diameter, but it initially decreases then rises on large canals. Al-Suhaili et al. (2014) studied rectangular sharp-crested weirs with three rectangular bottom openings of equal and unequal sizes and compared the results to the results of ANN models. Obead and Hamad (2014) studied triangular sharp-crested weirs of parabolic bottoms combined with rectangular gates and proposed a discharge equation for free and submerged flow. Severi et al. (2014) carried out laboratory experiments on cylindrical weir-gate structures and developed empirical relationships of discharge coefficient for over, combined and under flows. Shayan et al. (2014) proposed relationship for contraction coefficient to estimate the discharge coefficient for flow under sluice and radial gates at free and submerged flow conditions.

From the review of literature, it appears that different combinations of weir-gate devices were used, and that the semi-cylindrical gate-weir structure has not been studied previously (to the best of the authors' knowledge). This device is relatively simple, economical and easy to use. The aim of the current study is to investigate the performance of flow through the semi-cylindrical structure and the contribution of the weir flow and gate flow in the total discharge of the structure.

\section{THEORETICAL BACKGROUND AND DIMENSIONAL ANALYSIS}

The fundamentals used for analyzing the simultaneous flow through the combined structure illustrated in Figure 1 are based on the individual physical and geometrical parameters of the weir and the gate, as they are operating separately Chow (1959), French (1986) and Subramanya (1986).

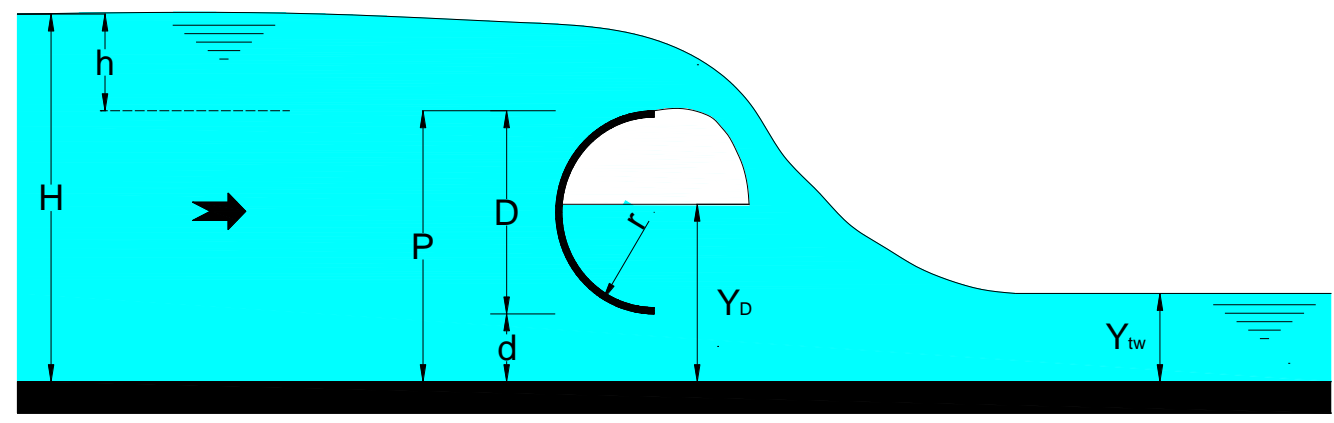

Fig. (1): Definition sketch of the thin-plate semi-cylindrical structure.

The upper flow is free flow over the weir and the underneath flow is the gate flow. The gate flow is free when the upstream depth does not exceed the weir crest. But when the weir begins to operate, the interaction of the two flow parts causes submergence of the gate. The equation for the combined discharge $Q_{a c t}$ may be written as the summation of the discharge passing over the weir
$Q_{\text {weir }}$ and the discharge passing under the gate $Q_{\text {gate }}$ :

$$
Q_{a c t}=Q_{\text {weir }}+Q_{\text {gate }}
$$


Equation (1) may be written as:

$$
Q_{a c t}=C_{\text {weir }}\left[\frac{2}{3} B \sqrt{2 g} h^{3 / 2}\right]+C_{g a t e}\left[B \cdot d \sqrt{2 g\left(H-Y_{t w}\right)}\right]
$$

where $C_{\text {weir }}$ is the discharge coefficient of the weir, $C_{\text {gate }}$ is the discharge coefficient of the gate, $B$ is the channel width (L), and $g$ is the acceleration due to gravity $\left(\mathrm{L} / \mathrm{T}^{2}\right)$. Basically, if any of these two flows occur alone without the effects of the other, it is possible to separate the factors controlling each flow. The main factors affecting the separate weir flow are the head over the weir crest $h$, height of the weir crest $P$, and radius of the weir $r$. On the other hand, the factors affecting the separate gate flow are the upstream flow depth $H$, height of the gate opening $d$, and the downstream flow depth $Y_{t w}$, when the gate operates alone.

The dimensional analysis for flow over and under cylindrical structure is widely explained in Armaghan et al. (2014) study, the dimensionless functional relationship for each flow component can be written as:

$$
\begin{aligned}
& C_{\text {weir }}=f(h, p, r, \text { Fluid chacteristics, Channel prop. }) \Rightarrow f\left(\frac{h}{P}, \frac{h}{r}\right) \\
& C_{\text {gate }}=f\left(H, d, Y_{t w}, \text { Fluid chacteristics, Channel prop. }\right) \Rightarrow f\left(\frac{H}{d}, \frac{H}{Y_{t w}}\right)
\end{aligned}
$$

The weir height $p$ includes cylinder diameter and gate opening $(p=2 r+d)$ and $p$ is included in the upstream head $(H=h+p)$ so it can be replaced by $H$ in Equation (3) to get a dimensionless parameter (percentage) combining and explaining the head on weir to the head on gate when they operate simultaneously. Moreover, the parameter $h / d$ combines the contribution effect of both of them. Accordingly, the dimensionless $Q_{a c t}$ will be a function of the following dimensionless parameters:

$\frac{Q_{a c t}}{B \cdot d \sqrt{2 g d}}=f\left(\frac{h}{H}, \frac{h}{r}, \frac{H}{d}, \frac{H}{Y_{t w}}, \frac{h}{d}\right)$

\section{EXPERIMENTAL WORK}

The experimental tests were performed in the Hydraulic Laboratory of the College of Engineering, University of Duhok using a horizontal rectangular flume $5 \mathrm{~m}$ long, $0.3 \mathrm{~m}$ wide and $0.45 \mathrm{~m}$ deep. It was equipped with a manually adjusted valve to control the flow quantity. The flow rate was measured by an electro-magnetic flow meter and the water surface elevations were measured using point gauges. The tested models were made of a $1 \mathrm{~mm}$ thick steel plate and sealed in position in the flume using silicon glue.

Sixteen semi-cylindrical combined gate-weir devices were tested. The models are classified as four sets (A, B, C, D) with four different diameters $D=6,7,9$ and $12 \mathrm{~cm}$, respectively. Four different gate openings were investigated $d=$ 2, 3, 4 and $5 \mathrm{~cm}$, as shown in Table 1 . In addition, one rectangular thin-plate model of $12 \mathrm{~cm}$ height was tested for the purpose of comparison. This additional model is classified as set (E) in Table (1). The rage of discharge is between 9.42 to $33.25 \mathrm{l} / \mathrm{s}$ and the upstream water depth between 104.2 and $235.1 \quad \mathrm{~mm}$. 
Journal of University of Duhok, Vol. 21, No.2 (Pure and Eng. Sciences), Pp 45-58, 2018

https://doi.org/10.26682/sjuod.2018.21.2.5

Table( 1): Details of the experimental models

\begin{tabular}{|c|c|c|c|c|c|c|c|c|c|c|c|c|c|c|c|c|c|c|c|}
\hline \multirow[b]{2}{*}{ Set $A$} & \multirow[b]{2}{*}{$D(\mathrm{~cm})$} & \multirow[b]{2}{*}{$d(\mathrm{~cm})$} & \multicolumn{8}{|c|}{ Semi-cylindrical Models } & \multicolumn{9}{|c|}{ Rectangular Model } \\
\hline & & & $d / D$ & Set B & $D(\mathrm{~cm})$ & $d(\mathrm{~cm})$ & $d / D$ & Set C & $D(\mathrm{~cm})$ & $d(\mathrm{~cm})$ & $d / D$ & Set D & $D(\mathrm{~cm})$ & $d(\mathrm{~cm})$ & $d / D$ & Set E & $D(\mathrm{~cm})$ & $d(\mathrm{~cm})$ & $d / D$ \\
\hline 1 & 6 & 2 & 0.333 & 5 & 7 & 2 & $\begin{array}{c}0.28 \\
6 \\
\end{array}$ & 9 & 9 & 2 & 0.222 & 13 & 12 & 2 & $\begin{array}{c}0.16 \\
7 \\
\end{array}$ & 17 & 12 & 2 & 0.167 \\
\hline 2 & 6 & 3 & 0.5 & 6 & 7 & 3 & $\begin{array}{c}0.42 \\
9 \\
\end{array}$ & 10 & 9 & 3 & 0.333 & 14 & 12 & 3 & 0.25 & 18 & 12 & 3 & 0.25 \\
\hline 3 & 6 & 4 & 0.666 & 7 & 7 & 4 & $\begin{array}{c}0.57 \\
1 \\
\end{array}$ & 11 & 9 & 4 & 0.444 & 15 & 12 & 4 & $\begin{array}{c}0.33 \\
3 \\
\end{array}$ & 19 & 12 & 4 & 0.333 \\
\hline 4 & 6 & 5 & 0.833 & 8 & 7 & 5 & $\begin{array}{c}0.71 \\
4\end{array}$ & 12 & 9 & 5 & 0.556 & 16 & 12 & 5 & $\begin{array}{c}0.41 \\
7\end{array}$ & 20 & 12 & 5 & 0.417 \\
\hline
\end{tabular}


The models are tested under various submerged flow conditions, as shown in Figure 2. For each model, a series of different inflow rates were applied. A total number of 206 runs were completed during the experimental course.

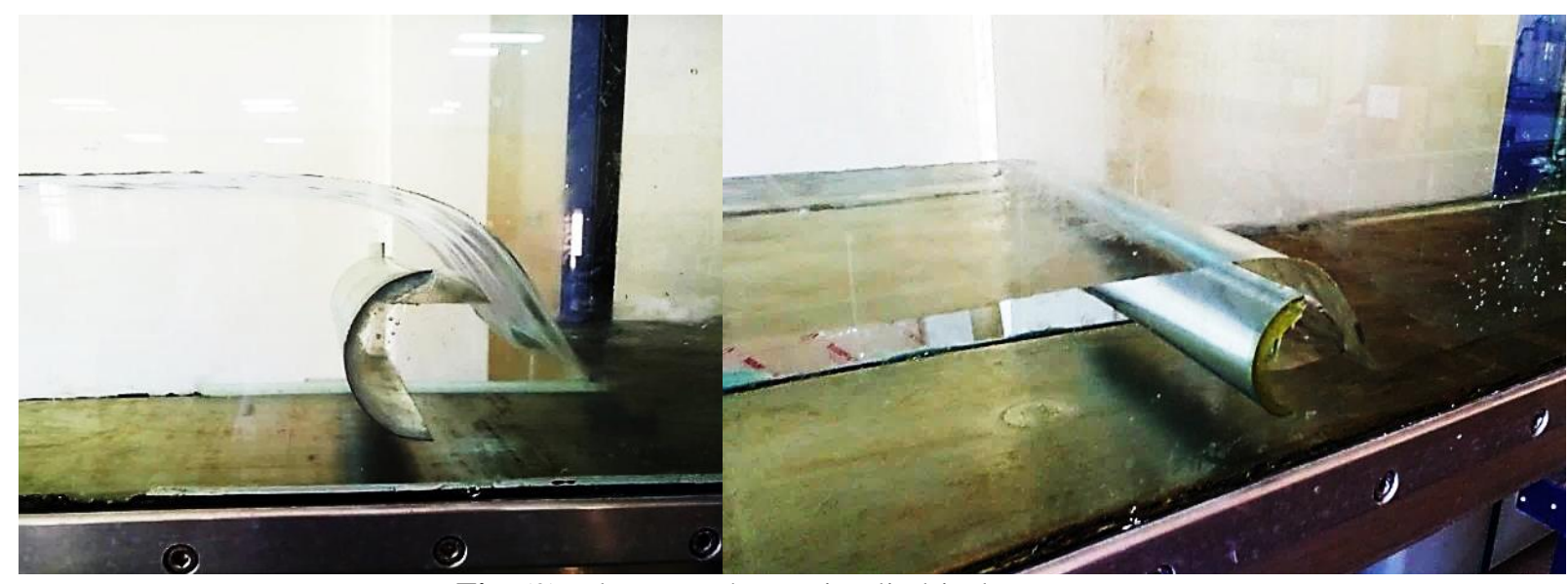

Fig. (2): Flow past the semi-cylindrical structure.

\section{RESULTS AND DISCUSSION}

The curvature of the semi-cylindrical structure affects the streamlines shapes and then reduces the energy loss. Comparison is carried out between this structure and a thin-plat of $12 \mathrm{~cm}$ to find the percentage advantage of this structure for the same upstream flow depth $H$. The percentage advantage in the performance of this structure relative to the thin-plate has been found to be $21 \%, 26 \%, 31 \%$ and $38 \%$ for $d=2,3,4$ and $5 \mathrm{~cm}$, respectively . Figure 3 shows the performance of the two shapes for $d=3 \mathrm{~cm}$. This increase in discharge is believed to be due the smoother curvature of streamlines when particles pass through the semi cylindrical shape as compared to the vertical plate.

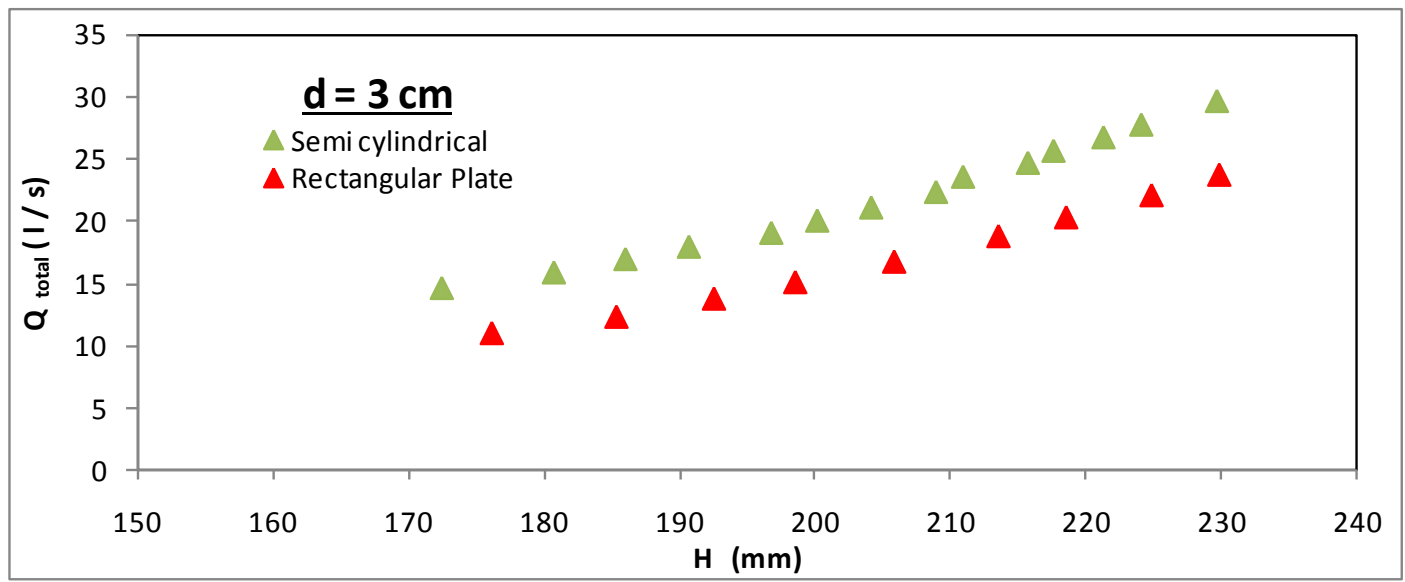

Fig. (3): Discharge versus upstream depth for semi-cylindrical and rectangular structures.

The collected measures of actual discharge and the upstream head for all runs are displayed in Figure 4, which shows four groups of curves, each group represents a cylinder diameter $D$. In each of these groups the effect of gate opening $d$ clearly appears at low heads. The axiomatic fact states that the discharge increases with the increase of gate opening for the same value of head. The proportionality of the increases vanishes as $H$ increases, the effect of $d$ is minimized and the curves of each group come to create nearly one curve. The effect of $d$ is reduced by the increase in 
the contribution of the weir. The weir discharge increases more rapidly with the increase of head due to the power $\left(h^{3 / 2}\right)$. When the water level starts to exceed the crest of weir, the falling water from the weir influences the gate flow. The increasing process of the total discharge due to increase in gate opening continues but in declines values.
Within the limitation of the experimental data the percentage increase in total discharge due to the increase in gate opening from 2 to $5 \mathrm{~cm}$ is about $80 \%$ for a constant head just above the weir crest. This percentage decreases to $3 \%$ for an increase in head

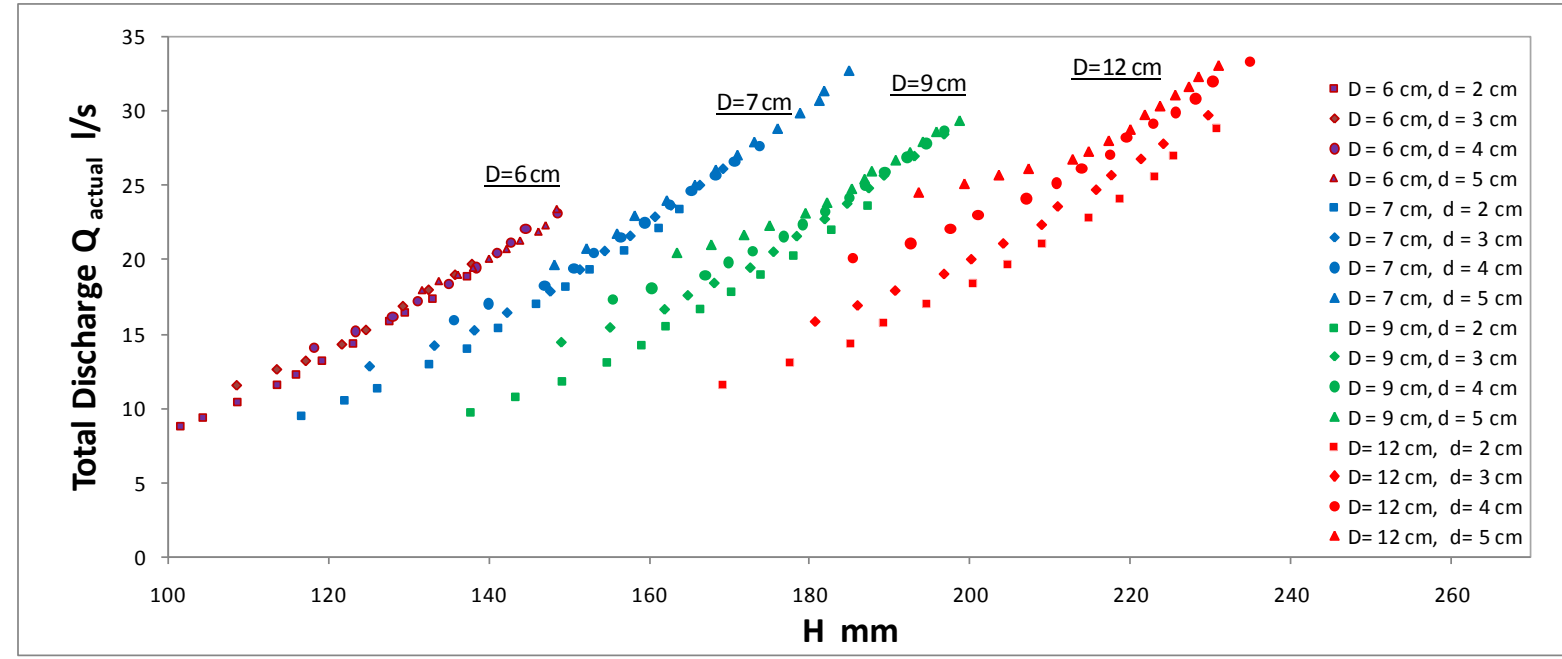

Fig. (4): Variation of the total actual discharge with the total upstream head.

The relation of $h$ with $Q_{a c t}$ for different sizes of the cylindrical structure is presented in Figure 5. It illustrates that at constant $d$, for a certain $h$ the value of $Q_{a c t}$ is more for the bigger cylinder sizes. accumulate upstream the structure for the same head over the weir. It can be also noticed that when $h$ increases the effect of $D$ decreases due to the increased contribution of the weir. A bigger diameter causes more head to

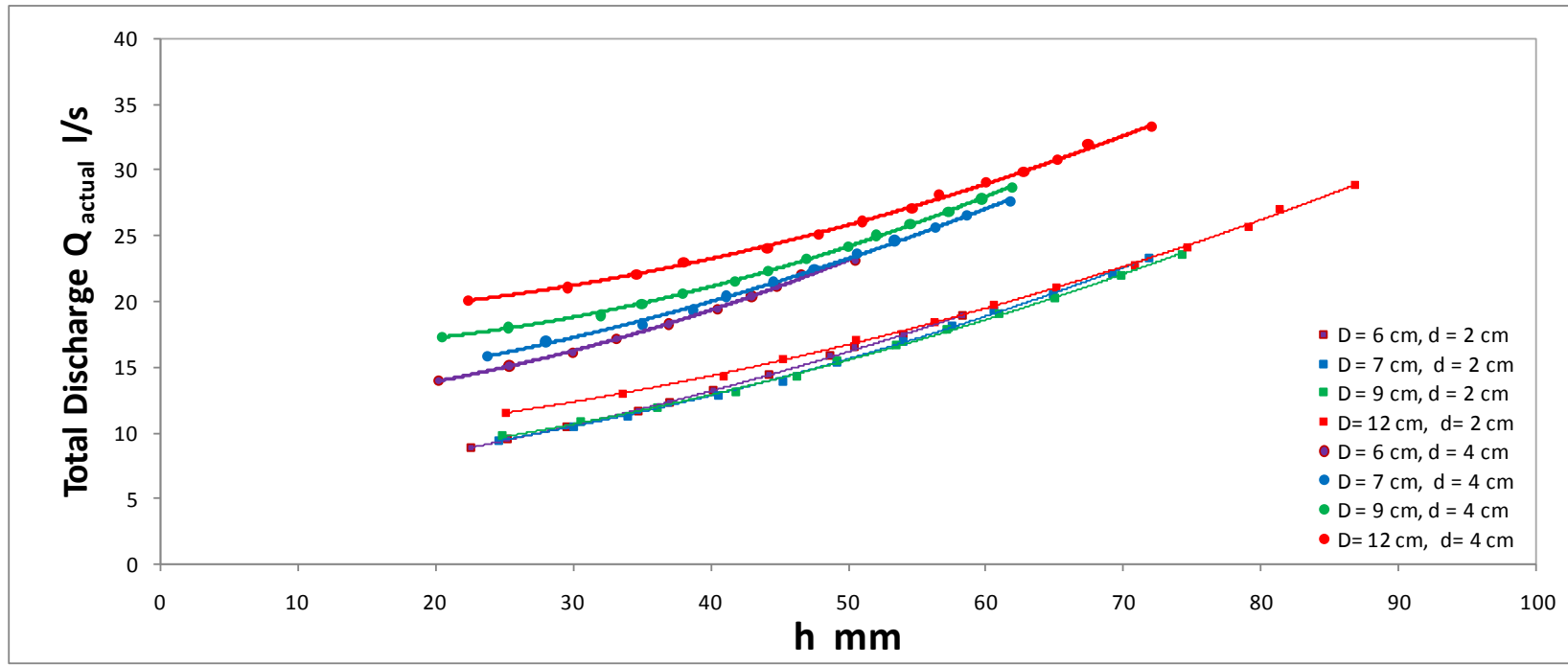

Fig. (5): Variation of total actual discharge with head over the weir. 
The dimensionless dependent variable and the dimensionless independent variables in Equation (5) have been calculated from the experimental data. Statistical correlation has been carried on to find the correlation factors between variables, which shows that the variable $(h / d)$ has the highest correlation factor then the variable $(H / d)$ with values of 0.971 and 0.911 with the dimensionless discharge, respectively, as shown in Table 2.

Table (2): Dimensionless discharge correlations with the dimensionless parameters

\begin{tabular}{cccccccc}
\hline & & Dimensionless $\mathbf{Q}$ & $\mathbf{h} / \mathbf{H}$ & $\mathbf{h} / \mathbf{r}$ & $\mathbf{H} / \mathbf{d}$ & $\mathbf{H} / \mathbf{Y}_{\mathrm{tw}}$ & $\mathbf{h} / \mathbf{d}$ \\
\hline dimensionless $Q_{\text {act }}$ & Pearson Correlation & 1 & $.677^{* *}$ & $.441^{* *}$ & $.911^{* *}$ & $.269^{* *}$ & $.971^{* *}$ \\
\hline & Sig. (2-tailed) & & .000 & .000 & .000 & .000 & .000 \\
\cline { 2 - 8 } & $\mathrm{N}$ & 199 & 199 & 199 & 199 & 199 & 199 \\
\hline
\end{tabular}

** Correlation is significant at the 0.01 level (2-tailed).

The dimensionless $Q_{a c t}$ increases with the increase of $(h / d)$ for all models, as shown in Figure 6. It is useful to note that for low values of $(h / d)$ the effect of $D$ is clear on the discharge, the bigger is $D$ the more is the discharge. The reason of that is the increase of head on the gate and at the same time the gradual surface curvature of the weir. However, the effect of $D$ is no longer notable when the value of $(h / d)$ increases to reach the value of 2 .

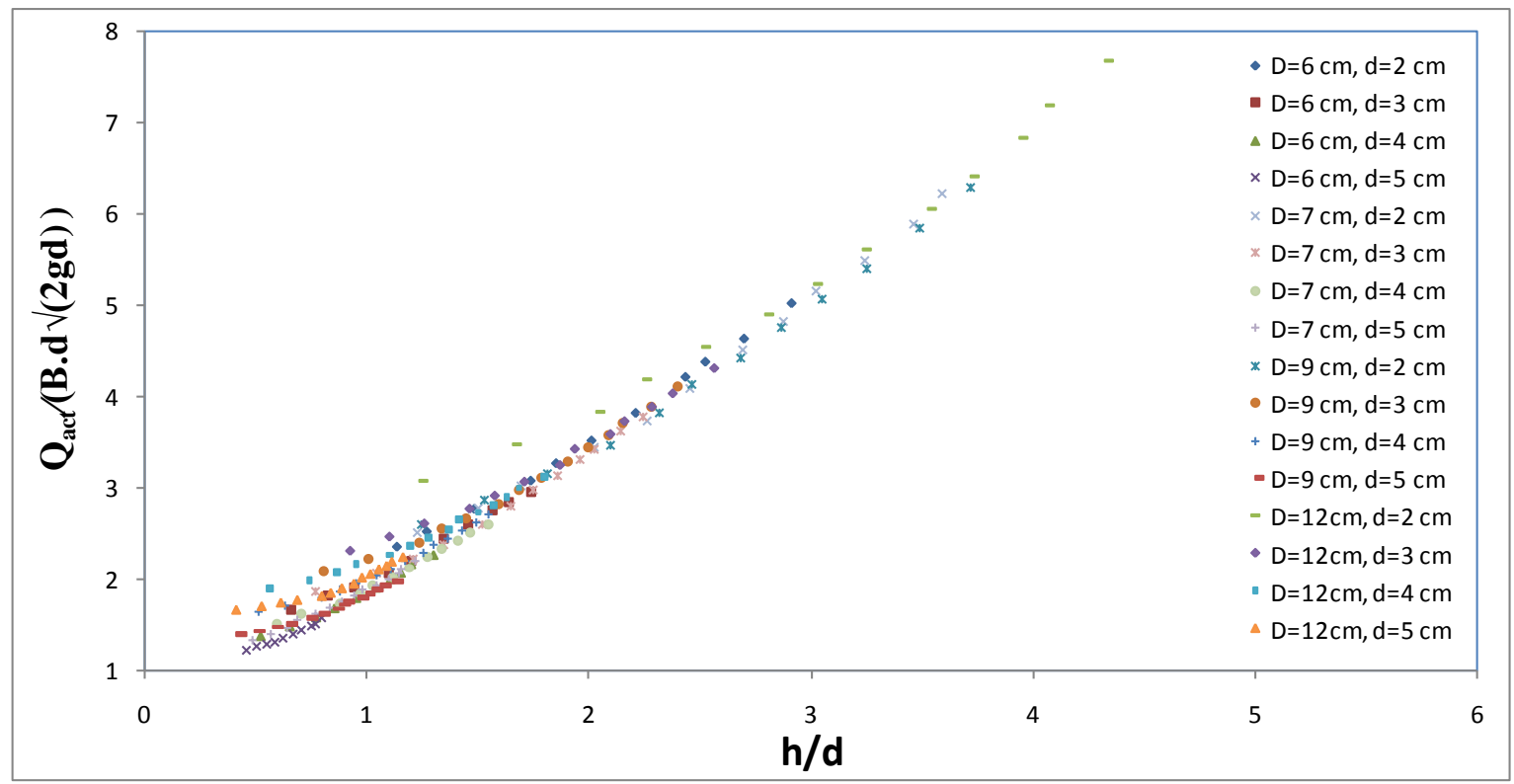

Fig. (6): Variation of the dimensionless total actual discharge with $h / d$.

Two groups of curves are presented in Figure 7 , the upper group presents the minimum gate opening in the study $(d=2 \mathrm{~cm})$ while the lower group presents the largest gate opening $(d=5 \mathrm{~cm})$.
It can be noted that for the range of $(h / H)$ between $(0.1-0.35)$ the first group performs better than the second group, this is due to the increased contribution of the weir in the flow than the gate. 


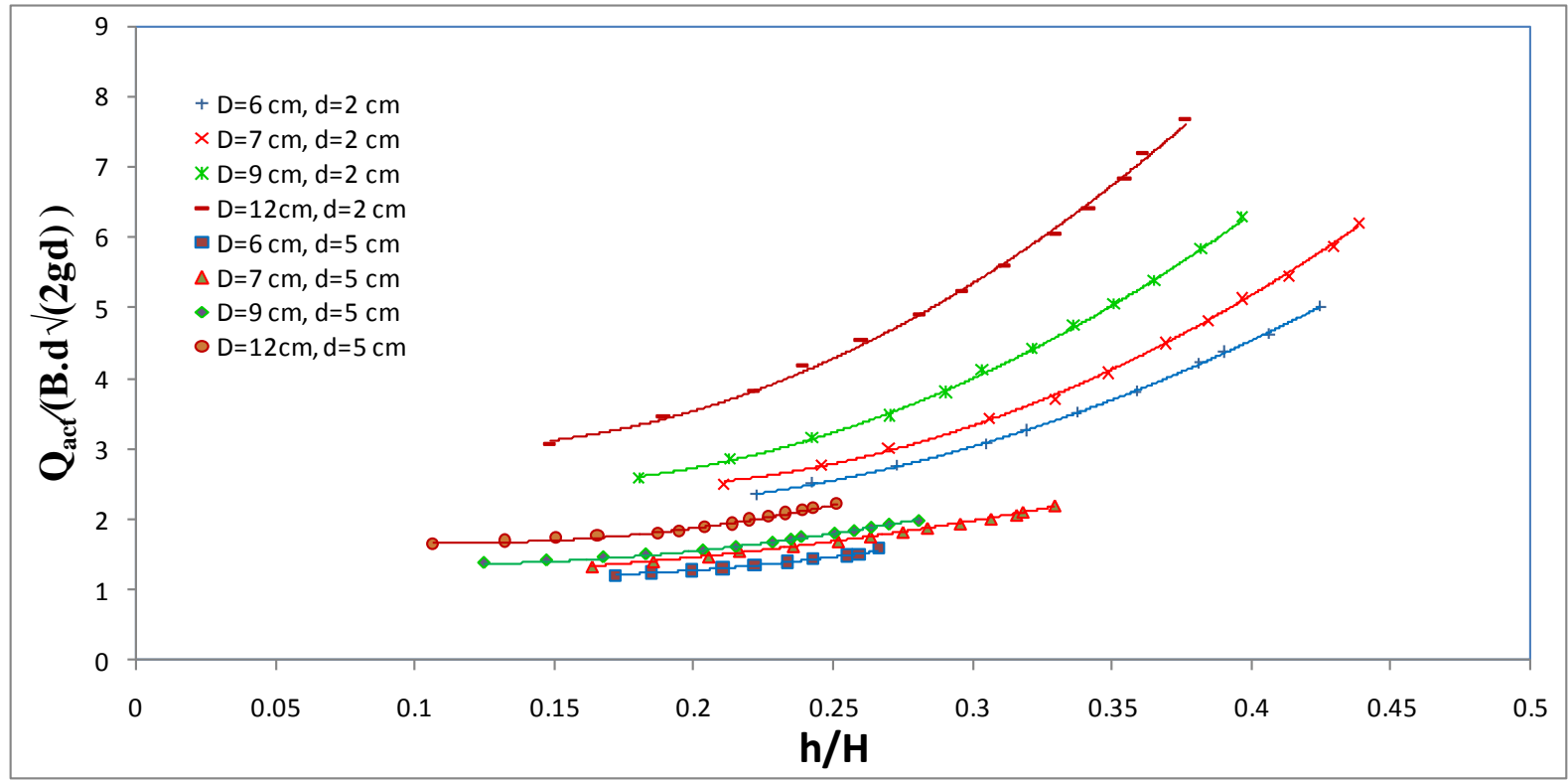

Fig. (7): Variation of dimensionless total actual discharge with $\mathrm{h} / \mathrm{H}$

The variation of the dimensionless $Q_{a c t}$ with the ratio of total head to gate opening $(H / d)$ is displayed in Figure 8. It shows that the dimensionless $Q_{a c t}$ increases with the increase of $(H / d)$. It also shows clearly the effect of $D$ on the value of discharge, if the range of the data demonstrated in Figure 8 be theoretically extended based on their trend equations then for a certain value of $(H / d)$ it appears that the cylinder of smaller diameter performs better. The smaller $D$ and constant value of $(H / d)$ means more head $h$ on the weir.

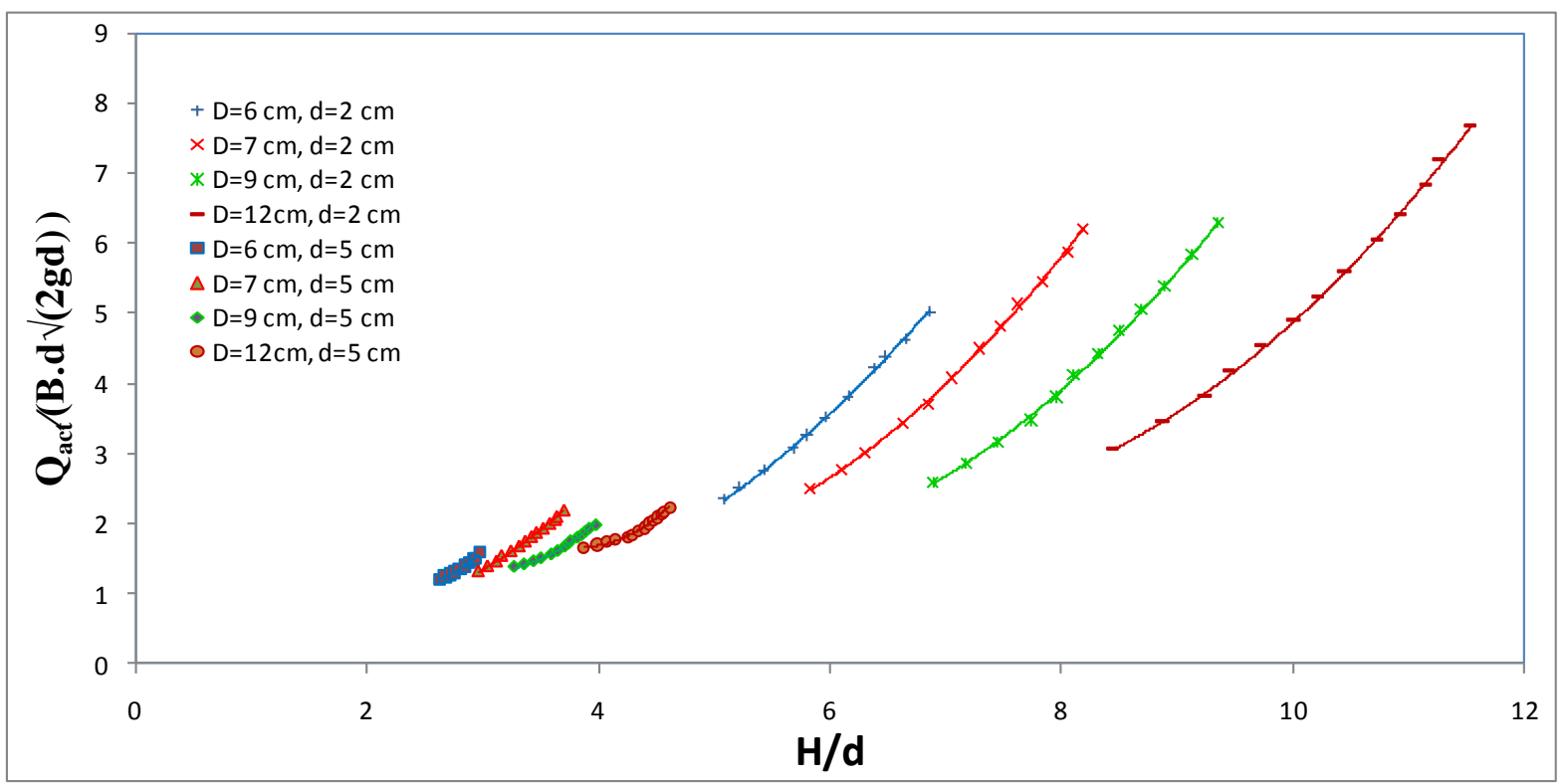

Fig. (8): Variation of dimensionless total actual discharge with $H / d$. 
With a bigger $D$ the curvature of the structure is more and this will affect the stream lines curvature to reach both the weir and gate. Figure 9 shows the increased performance of the structure with increased values of $(h / r)$. It shows that the structure of bigger $D$ performs better for a specific value of $(h / r)$.

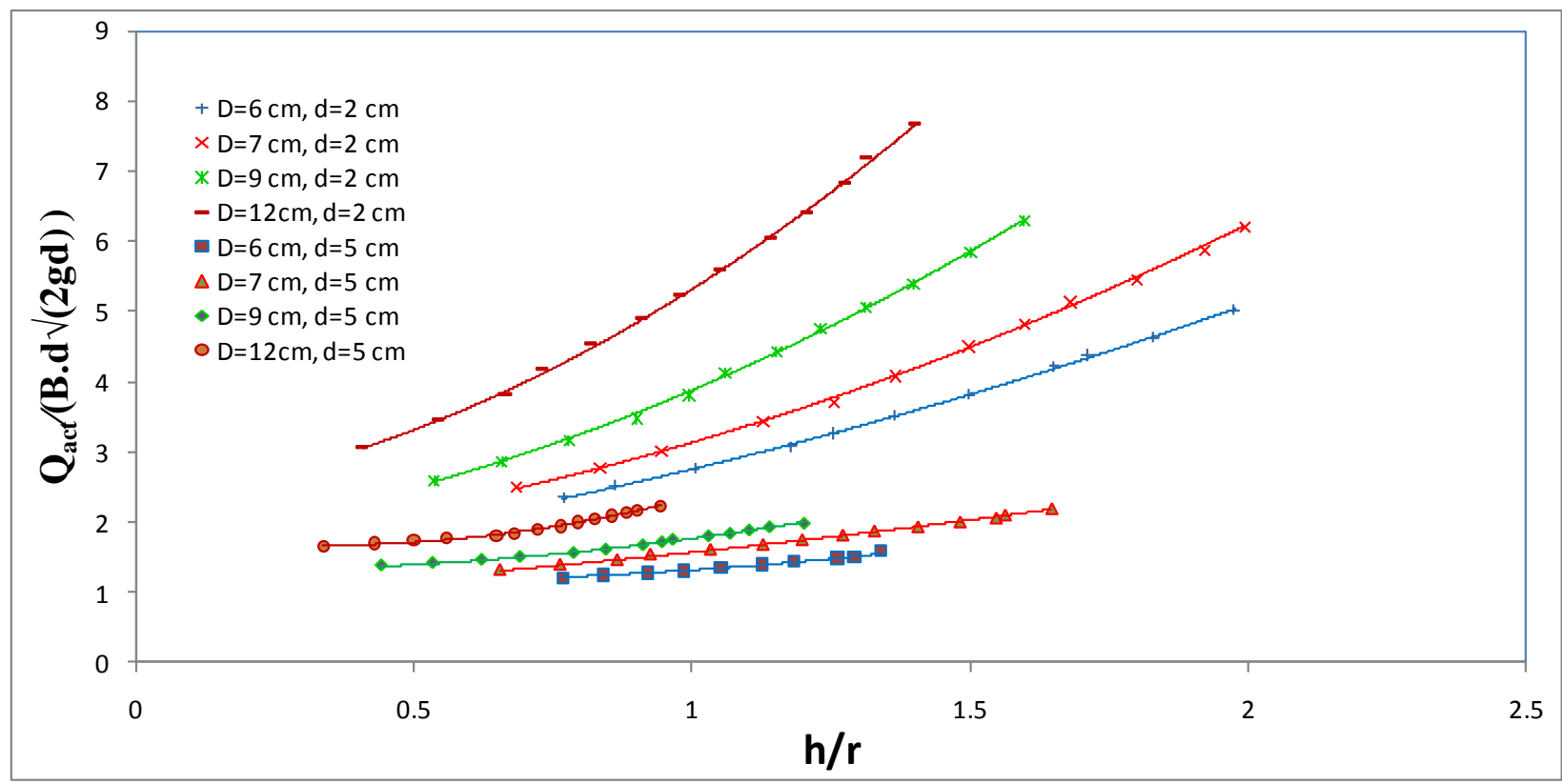

Fig. (9): Variation of the dimensionless total actual discharge with $h / r$.

The effect of the tail water depth $Y_{t w}$ on the performance of the structure is presented in Figure 10. It shows that $\left(H / Y_{t w}\right)$ decreases as the flow rate increases. This is because at higher flow rate, $\mathrm{Y}_{\mathrm{tw}}$ is more which reduces the value of $\left(H / Y_{t w}\right)$.

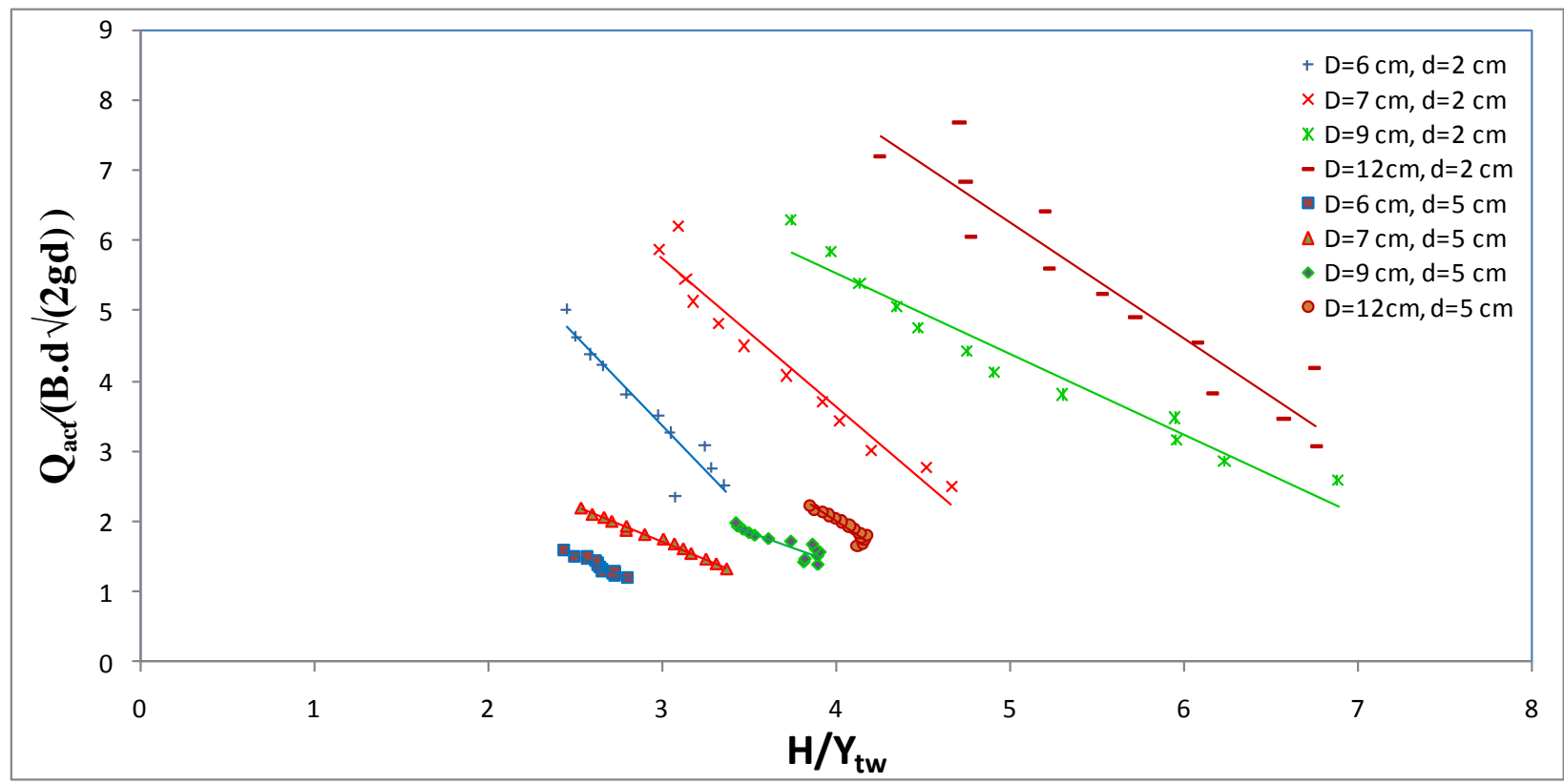

Fig. (10): Variation of dimensionless total actual discharge with $H / Y_{t w}$. 
The maximum rate of free flow passing through the gate $Q_{\text {free }}$ happens when the upstream water level is at the weir crest, before the contribution of the weir. The corresponding head is equal to the height of the weir crest. $Q_{\text {free }}$ can be calculated from Equation (2) using a coefficient of discharge that takes into account the curvature of the gate. Shayan et al. (2014) introduced $C_{d}$ for radial gate, Equation (7), based on the contraction coefficient $C_{c}$, Equation (6), which is a function of the gate lip angle in radians $\theta_{r}$ :

$$
\begin{aligned}
& C_{c}=1.001-0.2349 \theta_{r}-0.1843 \theta_{r}{ }^{2}+0.1133 \theta_{r}{ }^{3} \\
& C_{d}=\frac{C_{C}}{\sqrt{1+C_{C} \frac{d}{H}}}
\end{aligned}
$$

For all the experimental runs, the difference between $Q_{a c t}$ and $Q_{\text {free }}$ is calculated. If all that quantity be delivered by the weir only, the equivalent weir head $H^{*}$ is calculated from Equation (2).The dimensionless parameter $(H * / d)$ is calculated and compared with the dimensionless actual weir head $(h / d)$ obtained from the experimental measures. The comparison is presented in Figure 11 which shows that the values of $(h / d)$ are more than the calculated $\left(H^{*} / d\right)$. The average relative increase in the head $\left(\frac{h-H^{*}}{H^{*}}\right)$ is $34 \%$. This difference may be related to the submergence of the gate which fosters the build of the upstream head due to the obstruction of the gate flow. A linear model for this relationship is given in Equation (8) with $R^{2}=$ 0.987 .

$$
\frac{H^{*}}{d}=0.864 \frac{h}{d}-0.059 \frac{h}{r}
$$

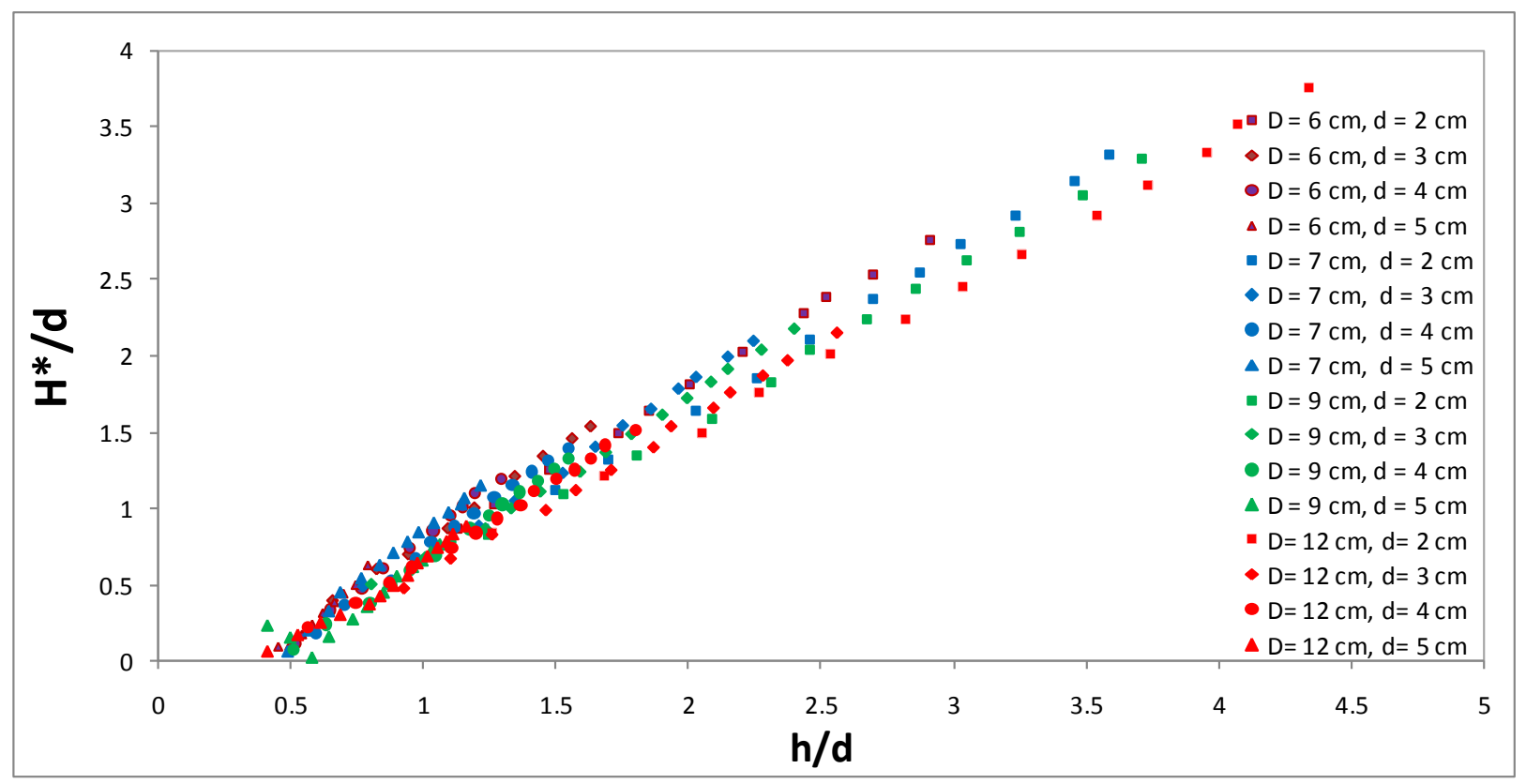

Fig. (11): Variation of $H^{*} / d$ with weir contribution $h / d$.

Linear and nonlinear regression is employed from the SPSS analysis to find useful mathematical models between the dependent dimensionless total discharge and the relating independent variables. To insure the best and simplest model, different regression models were tested four of them are listed in Table 3. 
Table (3): The regression models analysis for dimensionless discharge.

\begin{tabular}{ccc}
\hline No. & \multicolumn{1}{c}{ Equation } & $\mathbf{R}^{2}$ \\
\hline $\mathbf{1}$ & $\frac{Q_{a c t}}{b d \sqrt{2 g d}}=0.513+1.512 \frac{h}{d}$ & 0.943 \\
\hline $\mathbf{2}$ & $\frac{Q_{a c t}}{b d \sqrt{2 g d}}=1.530+1.638 \frac{h}{d}-4.245 \frac{h}{H}+0.084 \frac{H}{d}-0.135 \frac{H}{Y_{t w}}$ & 0.956 \\
\hline 3 & $\frac{Q_{a c t}}{b d \sqrt{2 g d}}=0.114\left(\frac{h}{d}\right)^{2}+1.060 \frac{h}{d}+0.858$ & 0.948 \\
\hline 4 & $\frac{Q_{a c t}}{b d \sqrt{2 g d}}=0.027\left(\frac{h}{d}\right)^{2}+9.883\left(\frac{h}{H}\right)^{2}+1.571 \frac{h}{d}-8.105 \frac{h}{H}+1.766$ & 0.958 \\
\hline
\end{tabular}

The listed models have nearly the same accuracy for predicting the dimensionless $Q_{a c t}$ but the simplest models to adopt are the linear ones. Two separate correlations were carried out for the weir and gate discharges and it was found that the parameters of highest correlation at the 0.01 level (2-tailed) are $(h / H, h / r)$ for the weir and $(H / d$, $\left.H / Y_{t w}\right)$ for the gate. According to these correlations a linear regression for the actual total discharge was carried out depending on the weir discharge and the gate discharge. The model is presented in

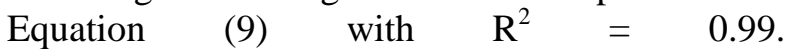

$$
Q_{a c t}=\left(0.891+0.121 \frac{H}{d}-0.117 \frac{H}{Y_{t w}}\right) Q_{\text {gate }}+\left(0.410-2.595 \frac{h}{H}+0.679 \frac{h}{r}\right) Q_{\text {weir }}
$$

The contribution of $Q_{\text {weir }}$ in $Q_{a c t}$ varies from $7 \%$ to $44 \%$ and thus the contribution of $Q_{\text {gate }}$ in $Q_{a c t}$ varies from $56 \%$ to $93 \%$, as presented in Figure 12. The relational models are presented in Equations (10) and (11) with $\mathrm{R}^{2}=0.995$ and 0.987 , respectively.

$$
\begin{aligned}
& \frac{Q_{\text {wier }}}{Q_{\text {act }}}=0.250 \frac{h}{r}+0.052 \frac{h}{d}-0.590 \frac{h}{H} \\
& \frac{Q_{\text {gate }}}{Q_{\text {act }}}=1.757 \frac{h}{H}+0.233 \frac{H}{Y_{t w}}-0.102 \frac{H}{d}
\end{aligned}
$$




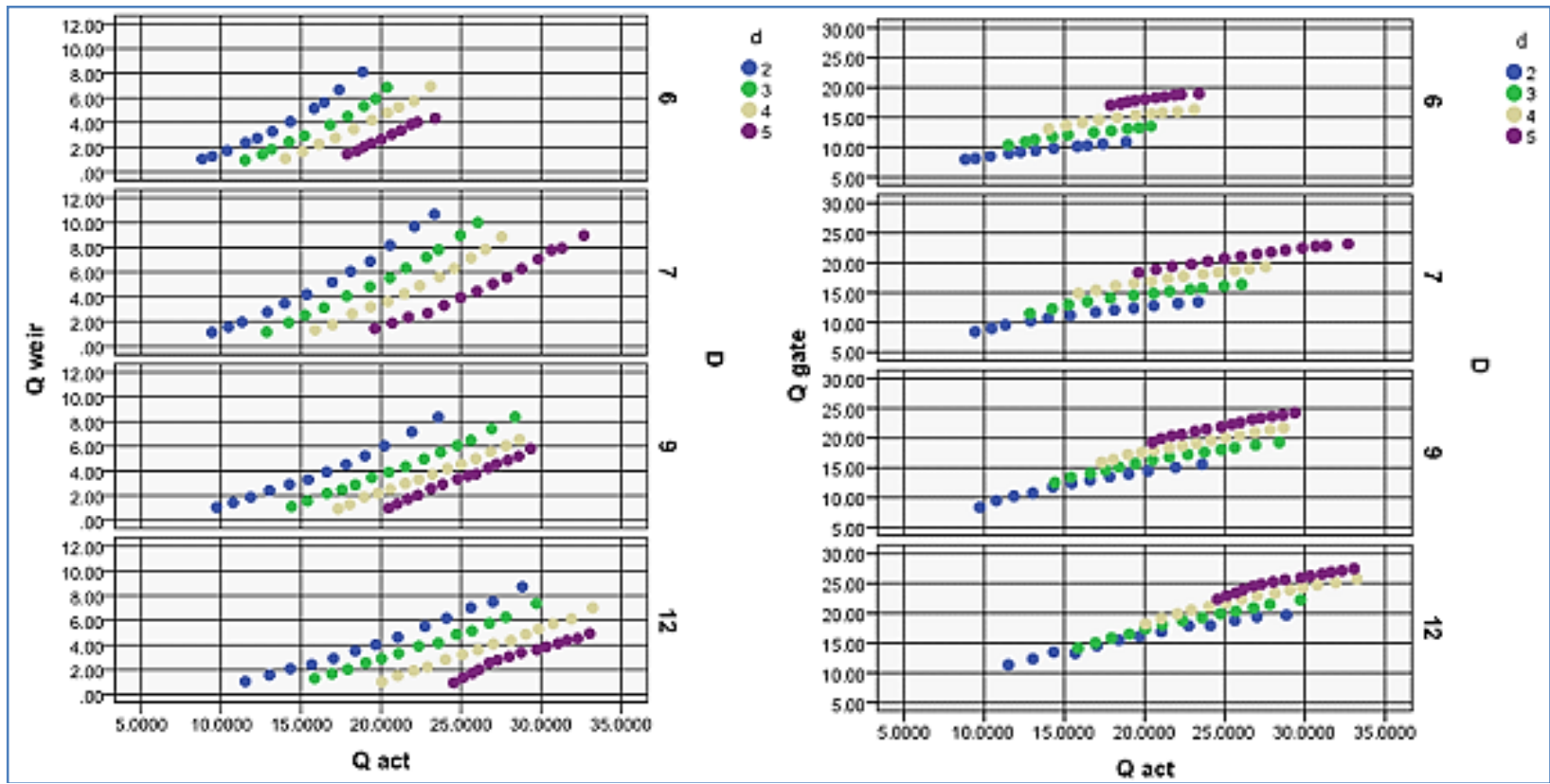

Fig. 12: Variation of the weir discharge and the gate discharge with the actual total discharge.

The weir discharge relative to that of gate is presented in Figure 13. A linear regression model is found with $\mathrm{R}^{2}=0.983$.

$\frac{Q_{\text {wier }}}{Q_{\text {gate }}}=0.543 \frac{h}{r}+0.114 \frac{h}{d}-1.889 \frac{h}{H}$
The contribution of the weir flow depends on the cylinder diameter $D$, and the gate opening $d$ as clear from Equation (9). The weir discharge is between $(6 \%-78 \%)$ of the gate discharge.

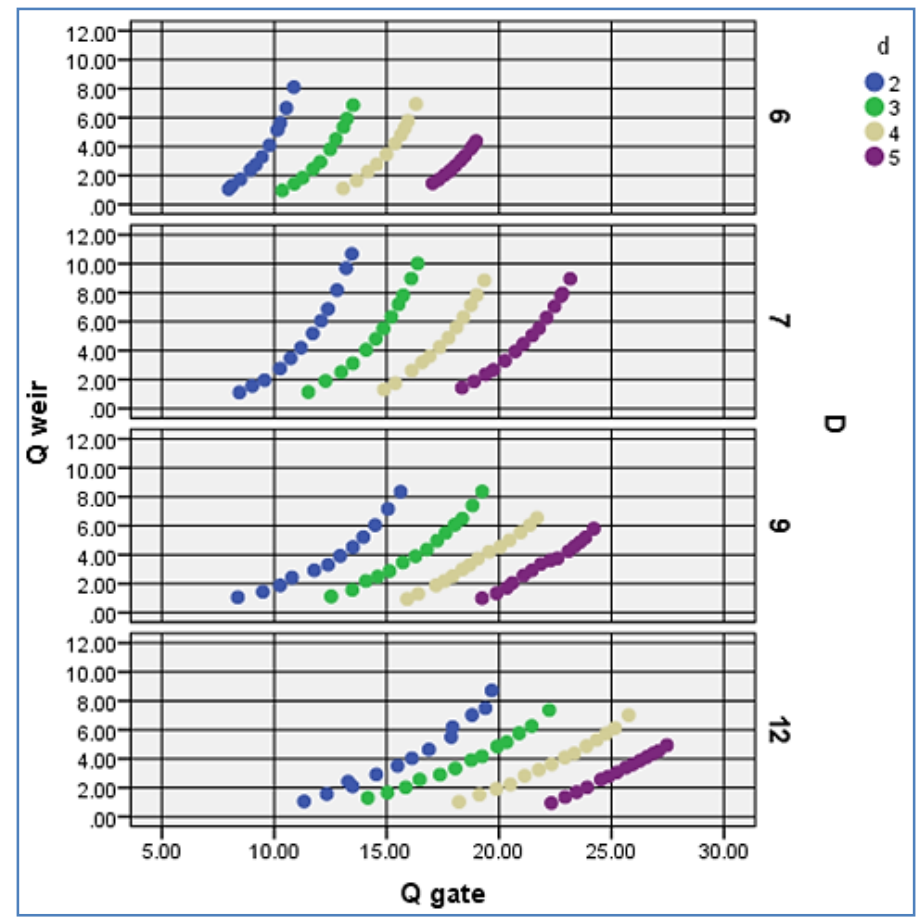

Figure 13: Variation of the weir discharge to the gate discharge. 


\section{CONCLUSIONS}

The simultaneous flow over the weir and through the gate of the semi-cylinder combined structure is investegated. Sixteen physical thinplate models are tested and 206 experimantal runs were completed. This structure is compared with a vertical rectangular thin-plate model. The following findings can be forwarded within the limitations of the present study.

1- The semi cylindrical shape causes an increase in discharge by $21 \%, 26 \%, 31 \%$ and $38 \%$ compared with the vertical plate for gate openings of 2, 3, 4 and $5 \mathrm{~cm}$, respectively.

2- The effect of gate opening $d$ on the actual total discharge decreases with the increase of the total flow depth $H$.

3- The effect of cylinder diameter $D$ on the coefficient of discharge decreases with the increase of head $h$.

4- The dimensionless discharge increases with increase in $\frac{h}{d}, \frac{h}{H}, \frac{H}{d}, \frac{h}{r}$ and decreases with increase in $\frac{\mathrm{H}}{Y_{t w}}$.

5- When the weir starts to contribute in the flow, a build-up upstream head occurs $\left(\frac{h-H^{*}}{H^{*}}\right)$ with an average value of $34 \%$.

6- Mathematical models are proposed for predicting the dimensionless discharge and total discharge.

7- The contribution of each of the weir and gate in the flow is represented in the mathematical model. The contribution of weir varies between $6 \%$ to $78 \%$ relative to the gate depending on the values of $D$ and $d$.

\section{REFERENCES}

- Alhamid, A. A., Husain, D., and Negm, A. M. (1996). Discharge Equation for Simultaneous Flow over Rectangular Weirs and below Inverted Triangular Weirs, Arab Golf Journal of Scientific Research, Vol. 14, No. 3, pp. 595-607.

- Alhamid, A. A., Negm, A. M., and Al-Brahim, A. M. (1997). Discharge Equation for Proposed Selfcleaning Device, Journal of King Saud University, Vol. 9, Engineering Science, No. 1, pp. 13-24.

- Alhamid, A. A. 2000, Discharge measurements in sewers using combined weir-gate device,
Hydraulic Engineering Software VIII, pp. 133142.

- Al-Suhaili, R. H., Al-Baidhani, J. H., and AlMansori, N. J. (2014). Hydraulic Characteristics of a Rectangular Weir Combined with Equal and Unequal Size Three Rectangular Bottom Openings, International Journal of Computational Engineering Research, Vol. 4, Issue 1, pp. 13-29.

- Chow, V.T. (1959). Open-Channel Hydraulics, McGraw-Hill, pp. 74.

- Dehghani, A.A., Bashiri, H., and Dehghani, N. (2010). Downstream Scour of Combined Flow over Weirs and below Gates, River Flow Dittrich, Koll, Aberle \& Geisenhainer (eds), pp. 1201-1205.

- French, R.H. (1986). Open-channel hydraulics, McGraw Hill Book Co., NewYork, pp. 343-353.

- Hayawi, H. A., Yahia, A. A., and Hayawi, G. A. (2008). Free Combined Flow over a Triangular Weir and under Rectangular Gate, Damascus University Journal, Vol. 24, No. 1, pp. 9-22.

- Jalil, S. A., and Sarhan, S. A. (2013). Experimental Study of Combined Oblique Weir and Gate Structure, ARPN Journal of Engineering and Applied Sciences, Vol. 8, No. 4, pp. 306-315.

- Khassaf, S. I., Yost, S. A., and Abbas, H. A. (2013). Coefficient of Discharge for a Compound Weir Combined with Semicircular Gate, International Journal of Advance Research, Vol. 1, Issue 9, pp. 1-8.

- Khassaf, S. I., and Abbas, H. A. (2013). Study the Free Flow over Compound Weir and below Semi Circular Gate, International Journal of Scientific \& Engineering Research, Vol. 4, Issue 10, pp. 1486-1491.

- Masoudian, M., Fendreski, R., and Gharahgezlou, M. (2013). The effects of laboratory canal size and cylindrical weir-gate diameter on discharge coefficient, Technical Journal of Engineering and Applied Sciences, Vol. 3, No. 15, pp. 16301634. 
- Negm, A. M., Al-Brahim, A. M., and Alhamid, A. A. (2002). Combined-free Flow over Weirs and below Gates, Journal of Hydraulic Research, Vol. 40, No. 3, pp. 359-365.

- Negm, A. M. (2002). Modeling of Submerged Simultaneous Flow through Combined Weirs and Gates Devices, Proceedings of the $5^{\text {th }}$ International Conference on Hydro-Science and Engineering, Warsaw, Poland.

- Obead, I. H., and Hamad, R. (2014). Experimental Study of Coupled Flow through Combined Weir-Gate Structure, Journal of Babylon University, Engineering Sciences, Vol. 22, No. 1, pp. 151-161.

- Severi, A., Masoudian, M., Kordi, E., and Roettcher, K. (2014). Discharge coefficient of combinedfree over-under flow on a cylindrical weir-gate,
ISH Journal of Hydraulic Engineering, Vol. 21, No. 1, pp. 42-52.

- Shahabi, M., Nasser, T., Ahmad, D. A., Abdoulrasoul, T., and Reza, R. G. (2011). Experimental Investigation of the effect of Contraction on Scouring in Downstream of Combined flow over Weirs and below Gates, The $5^{\text {th }}$ SASTech, Khavaran Higher-education Institute, Mashhad, Iran.

- Shayan, K. H., Farhoudi, J., and Roshan, R. (2014). Estimation of Flow Discharge under the Sluice and Radial Gates Based on Contraction Coefficient. IJST Transactions of Civil Engineering, Vol. 38, No. C2, pp 449-463.

- Subramanya, K. (1986). Flow in open channels, First revised edition, $7^{\text {th }}$ reprint. Tata Mc-Graw-Hill Publishing Company Ltd., New Delhi, pp. 219226. 